\title{
Cincinnati Regional Incidence, Morbidity, and Mortality of Neonatal Foregut Defects and High Coincidence with Cardiovascular Malformations
} \author{
Greenberg ${ }^{1,6}$ \\ ${ }^{1}$ Divisions of Neonatology, Cincinnati Children's Hospital Medical Center, 3333 Burnet Avenue, Cincinnati, OH 45229, USA \\ ${ }^{2}$ Biostatistics and Epidemiology, Cincinnati Children's Hospital Medical Center, 3333 Burnet Avenue, Cincinnati, OH 45229, USA \\ ${ }^{3}$ Biomedical Informatics, Cincinnati Children's Hospital Medical Center, 3333 Burnet Avenue, Cincinnati, OH 45229, USA \\ ${ }^{4}$ Pediatrics, Cincinnati Children's Hospital Medical Center, 3333 Burnet Avenue, Cincinnati, OH 45229, USA \\ ${ }^{5}$ Genetics, Cincinnati Children's Hospital Medical Center, 3333 Burnet Avenue, Cincinnati, OH 45229, USA \\ ${ }^{6}$ Perinatal Institute, Cincinnati Children's Hospital Medical Center, 3333 Burnet Avenue, Cincinnati, OH 45229, USA
}

Alan P Kenny ${ }^{1,6 *}$, Meredith Tabangin ${ }^{2,6}$, Eric Hall ${ }^{3,6}$, Koryse Woodrooffe ${ }^{1,6}$, Wendy Lai ${ }^{4,6}$, Jareen Meinzen-Derr ${ }^{2,6}$, Robert J Hopkin ${ }^{5,6}$, and James M

\begin{abstract}
The first trimester fetal foregut generates organs from larynx to ligament of Treitz. The incidence and clinical impact of many of the 29 congenital malformations arising from the foregut organs remain under characterized. We performed a retrospective chart review on patients from a geographically defined area born between 2006 and 2008 admitted to Cincinnati Children's Hospital Neonatal Intensive Care Unit with diagnoses consistent with one or more congenital foregut malformations.

We found foregut malformations occurred in 1 in 801 births and determined the incidence for each individual foregut malformation, including some that have not previously been reported. We report a high rate of multiple congenital foregut malformations within an individual with coincidence of foregut malformations of $51.5 \%$, and a high association with cardiovascular malformations $(40 \%)$. Hospital stay was prolonged (32 days versus 5 days). Need for assisted feeding $(51 \%)$ and respiratory support $(27 \%)$ at discharge were higher when compared to control patients (12 and $6 \%$, respectively). Mortality was $7 \%$ in patients with foregut malformations. These data provide needed quantitation of the incidence, morbidity, and mortality related to congenital foregut defects present in inpatient neonates. The coincidence of foregut malformations with cardiovascular malformations underscores the need for further research into their coordinated embryologic formation to aid their prevention and treatment.
\end{abstract}

Keywords: Congenital foregut malformations; Regional incidence; Morbidity; Mortality; Congenital cardiovascular defects

\section{Introduction}

Congenital malformations remain the leading cause of neonatal death in the U.S. [1]. $3 \%$ of newborns present with congenital malformations; $1 \%$ require immediate surgical intervention after delivery [2,3]. Morbidity often continues beyond infancy, with subsequent need for hospitalizations and surgeries.

The embryonic foregut arises from endoderm progenitor cells established by 4 weeks (1-2 somites) of gestation and gives rise to many vital organs: thyroid, trachea, thymus, parathyroid, esophagus, lung, liver, biliary tract, pancreas, stomach, and duodenum [4-8]. Reciprocal signaling between the foregut endoderm and neighboring mesoderm (that later gives rise to the heart, major blood vessels, and diaphragm) mediates normal organogenesis [9-13]. Malformations of these structures arise from defective budding, differentiation or sub regionalization during the first trimester (Supplementary Table 1).

Population-based clinical genetic approaches have begun to establish new molecular insights into foregut malformations, e.g., Fog2 with congenital diaphragmatic hernia [14,15]. In addition, investigations using murine models have recreated certain well known human foregut defects such as esophageal atresia and tracheoesophageal fistula implicating specific molecular pathways in foregut organ development [4,16]; only some of these identified defects have been examined in relevant patients [17-23].

Here we report the incidence of foregut malformations among NICU admissions over a 3-year interval from a geographically defined Greater Cincinnati region. Our data defines the coincidence between distinct foregut malformations and the prevalence of accompanying congenital cardiovascular malformations. Of note we report a high coincidence of congenital cardiovascular defects with foregut organ defects. We also report the neonatal morbidity and mortality associated with these congenital foregut malformations. This study provides baseline data for future studies combining epidemiology and molecular embryology to advance our understanding of foregut birth defects.

\section{Methods}

Cincinnati Children's Hospital Medical Center serves as the only center providing specialized care in the referral area for neonates born in Cincinnati Children's Perinatal Outreach Program (CCPOP) Region I (Figure 1), yielding population-based numerators and denominators to determine the incidence of individual and aggregate congenital foregut malformations. Data was gathered through chart review on neonatal patients born alive and admitted to Cincinnati Children's Hospital Medical Center Neonatal Intensive Care Unit ('CCHMC NICU'). Presence of a foregut malformation was determined from diagnosis codes. Those matching known foregut malformations were

*Corresponding author: Alan P Kenny, Divisions of Neonatology, Cincinnat Children's Hospital Medical Center, 3333 Burnet Avenue, Cincinnati, OH 45229 USA, E-mail: alan.kenny@cchmc.org

Received April 19, 2013; Accepted May 16, 2013; Published May 20, 2013

Citation: Kenny AP, Tabangin M, Hall E, Woodrooffe K, Lai W, et al. (2013) Cincinnati Regional Incidence, Morbidity, and Mortality of Neonatal Foregut Defects and High Coincidence with Cardiovascular Malformations. J Neonatal Biol 2: 115. doi:10.4172/2167-0897.1000115

Copyright: (c) 2013 Kenny AP, et al. This is an open-access article distributed under the terms of the Creative Commons Attribution License, which permits unrestricted use, distribution, and reproduction in any medium, provided the original author and source are credited. 


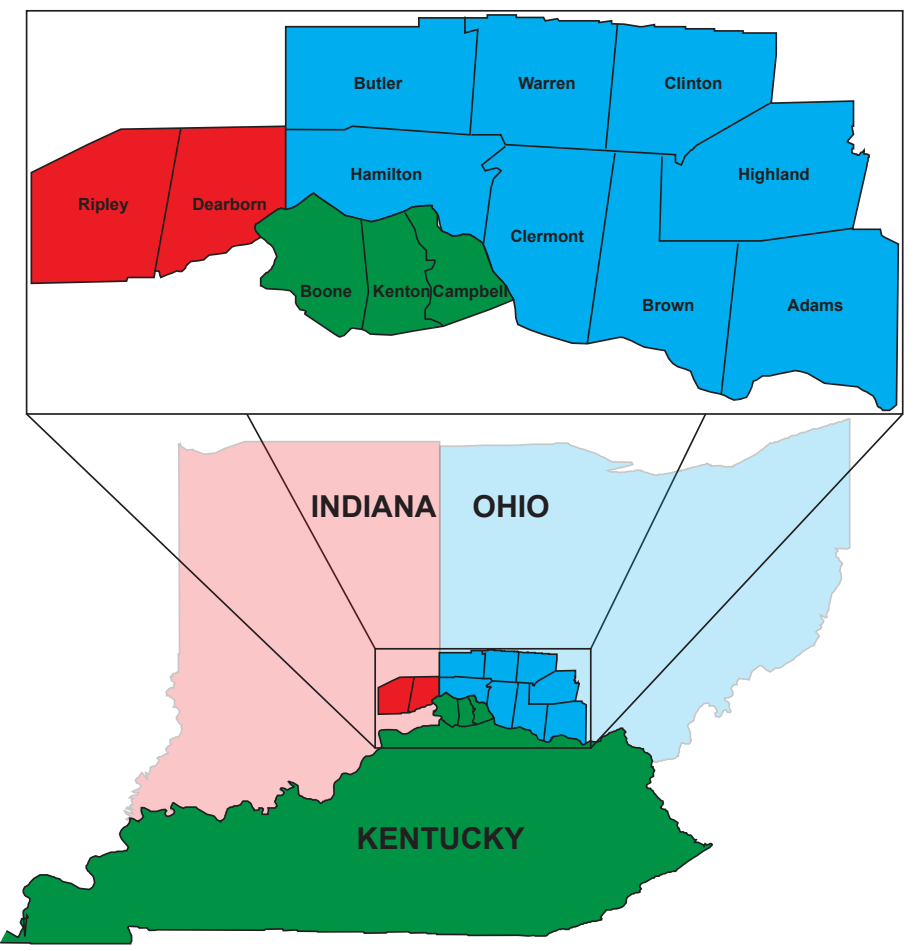

Figure 1: Cincinnati Children's Perinatal Outreach Program (CCPOP) Region I includes counties from Ohio, Indiana, and Kentucky.

included (Supplementary Table 1). Data was collected for the period between 1/1/2006 through 12/31/2008 from individuals residing in Zip Codes within CCPOP Region I.

Demographic and clinical data were retrieved from existing medical records under an IRB approved protocol. Patients with a confirmed foregut malformation diagnosis were further evaluated for gestational age, birth weight, race, maternal age, zip code of residence, and APGAR scores. Outcome data gathered included length of stay (days), disposition (home, death, transferred to another care facility), discharge requiring feeding support (including nasogastric tube or percutaneous gastrostomy tube), discharge home requiring respiratory support (home ventilator, tracheostomy, or nasal cannula).

Two distinct populations of control patients were used to compare morbidity and mortality: 1) All CCHMC NICU patients born in the region during the same time period without a congenital foregut malformation diagnosis (patient characteristic data unavailable) and 2) patients admitted with a postnatal surgical foregut condition (a non-congenital foregut malformation), pyloric stenosis, for which patient characteristic data were gathered.

We compared morbidity and mortality for all patients with congenital foregut malformations and for the most common individual congenital foregut diagnoses to pyloric stenosis controls. Differences in admission day of life and length of stay were tested using the Wilcoxon Rank Sum test. Differences in proportions were tested using a chi-square test or Fisher's exact test. Significance was declared using an alpha level of 0.05. Among comparisons by diagnosis subgroup, we used a conservative critical significance level of alpha $=0.002$ to adjust for an inflated Type I error due to multiple testing. Statistical analyses were conducted using SAS version 9.2 (SAS Institute, Cary, NC).

\section{Results}

High total incidence of congenital foregut malformation patients requiring neonatal care

The total incidence of patients with foregut malformations has not been reported to date. We found 114Region I patients diagnosed with foregut malformations requiring care in CCHMC NICU. Since 91299 births occurred in the region, we determined an aggregate foregut malformation incidence of 1 in 801 . Given that 2264 patients born within Region I received care at CCHMC NICU during this period, foregut malformations were associated with 1 in 20NICU admissions. Thus congenital foregut malformations as a whole are common in our region and in our referral NICU.

\section{Individual incidence of congenital foregut malformations requiring neonatal care}

Published incidences of foregut malformations and our regional incidence for each distinct foregut malformation are shown in table 1. Some conditions falling under the foregut malformation category were not observed during this period (congenital high airway obstruction syndrome, laryngotracheal cleft, bronchogenic cyst, congenital lobar emphysema, and choledochal duct cyst). The most common conditions include congenital malrotation at the Ligament of Treitz and the airway malacias (48 unique patients with at least one of the airway malacias [1:1902], laryngomalacia, tracheomalacia, and bronchomalacia). The least common presenting foregut diagnoses were esophageal web, lung lobe agenesis, diaphragmatic eventration, and congenital diabetes mellitus.

\section{Coincidence of one foregut malformation with another}

Embryonic stage signaling within and between distinct regions of the embryonic foregut might result in coincidence of one congenital 


\begin{tabular}{|c|c|c|c|c|c|}
\hline & & & Incidence & & \\
\hline Foregut Region & Diagnosis & \multicolumn{2}{|c|}{ This Report (1:) } & Reported (1:) & References \\
\hline \multirow[t]{2}{*}{ Esophagus } & EA-TEF & 4348 & & $2500-3922$ & Depaepe and others, 1993 \\
\hline & Web & 91299 & & No Reported Data & Robert and others, 1993 \\
\hline Airway & Laryngomalacia & 3148 & \multirow{3}{*}{1902} & \multirow{3}{*}{2100} & Holder and others, 1964 \\
\hline & Tracheomalacia & 3512 & & & Boogard and others, 2005 \\
\hline & Bronchomalacia & 4565 & & & \\
\hline & Bronchus suis & 45650 & & 1000 & Barat and Conrad, 1987 \\
\hline Thyroid & Hypothyroidism & 15217 & & $2900-3600$ & Alm and others, 1984 \\
\hline \multirow[t]{4}{*}{ Lung } & CPAM & 45650 & & $25,000-35,000$ & Laberge and others, 2001 \\
\hline & Sequestration & 45650 & & 666 & Corbett and Humphrey, 2004 \\
\hline & Agenesis & 91299 & & 15,000 & Bentsianov and others, 2000 \\
\hline & Pulm Hypoplasia & 22825 & & 714 & Knox and Barson, 1986 \\
\hline \multirow[t]{2}{*}{ Diaphragm } & $\mathrm{CDH}$ & 8300 & & 2037 & Stege and others, 2003 \\
\hline & Eventration & 91299 & & $1400-12875$ & http://www.fetalultrasound.com \\
\hline Stomach & Microgastria & 22825 & & No Reported Data & Kroes and Feston, 1998 \\
\hline \multirow{2}{*}{ Pancreas } & Diabetes Mellitus & 91299 & & 400,000 & von Muhlendahl and others, 1995 \\
\hline & Annular Pancreas & 30433 & & $6667-8173$ & Ravitch, 1975 \\
\hline Duodenum & Duodenal Atresia & 8300 & & $5,000-10,000$ & Fonkalsrud and others, 1969 \\
\hline Ligament of Treitz & Malrotation & 3652 & & 500 & Welte and Grosso, 2007 \\
\hline Total Diagnoses & & 537 & & No Reported Data & \\
\hline Total Patients & & 801 & & No Reported Data & \\
\hline \multirow[t]{10}{*}{ Unrepresented } & CHAOS & & & No Reported Data & \\
\hline & Laryngotracheal Cleft & & & $625,000-2,000,000$ & Pezzettigotta and others, 2008 \\
\hline & Bronchogenic Cyst & & & No Reported Data & \\
\hline & Hypoparathyroidism & & & No Reported Data & \\
\hline & Thymic Hypoplasia & & & No Reported Data & \\
\hline & Lobar Emphysema & & & 25,000 & Nayar and others, 2005 \\
\hline & Alagille Syndrome & & & $70,000-100,000$ & Crosnier and others, 1998 \\
\hline & Choledochal Duct Cyst & & & $13,000-2,000,000$ & deVries and others, 2002 \\
\hline & Nesidioblastosis & & & No Reported Data & \\
\hline & Biliary Atresia & & & $3125-19,841$ & Zumkeller 1999 \\
\hline
\end{tabular}

Table 1: Regional and Reported Incidences of Individual Congenital Foregut Malformation Diagnoses.

foregut malformation with another: e.g., esophageal atresia with tracheoesophageal fistula and, less commonly, pulmonary sequestration with cystic adenomatoid malformation [24,25]. We observed a total of 170 malformations (malformation incidence of 1:531) in 114 patients, and Supplementary table 2 demonstrates that two or more coincident foregut malformations were observed in $51.5 \%$ of patients $(26.3 \%$ with two, $11.3 \%$ with three, $4.4 \%$ with four, $0.88 \%$ with five, and $0.88 \%$ with six coincident foregut malformations).

\section{Coincidence of cardiovascular and foregut malformations}

Embryonic stage signaling between endoderm and mesoderm play complementary instructive roles during early cardiovascular and foregut organ development [11,13,26,27]. Therefore, we investigated the frequency of foregut malformations with cardiac or major vascular malformations. Foregut malformations had a coincidence of $35.1 \%$ with either major vascular or cardiac defects.

13.2\% of patients with foregut malformations had an associated major vascular malformation (compared to $<1 \%$ reported in the general population, Table 2). These incidences exceed those reported in the general population for major vascular defects including subclavian artery and vena caval anomalies $[28,29]$.

Similarly we found excess incidence of cardiac malformations in foregut malformation patients above the general population (Table 2). Specific structural defects include: atrial septal defects [30-32], ventricular septal defects [30-34], atrioventricular canal, dextrocardia, tetralogy of Fallot, and double outlet right ventricle [31,35,36].

\section{Neonatal morbidity and mortality of patients with foregut malformations}

The aggregate mortality for neonates with congenital foregut malformations was 7\% (Table 3a, patient characteristic data in Supplementary Table 3), compared with no mortality for the control patients with pyloric stenosis. Of those neonates with congenital foregut malformation who survived to discharge, $51 \%$ required ongoing feeding support (nasogastric tube or percutaneous gastrostomy tube) compared with $12.5 \%$ of pyloric stenosis patients. Twenty-seven percent of patients with a congenital foregut malformation required respiratory support (nasal cannula or tracheostomy) at discharge compared with $6.3 \%$ of pyloric stenosis patient controls. Length of stay was also longer compared to the pyloric stenosis cohort (median [IQR] of $32[18,87]$ days versus $5[2,19]$ days versus $6.5[3,26.5]$ days, respectively). Compared with controls, patients with a congenital foregut malformation diagnosis are at increased risk for considerably higher morbidity and mortality.

Table 3a summarized outcomes for the common foregut malformation diagnoses. Of these, malrotation had the lowest morbidity and mortality. Laryngomalacia, the next most frequent diagnosis had three times the median length of stay and a significantly increased proportion requiring feeding support at discharge when compared with pyloric stenosis controls. Esophageal 
Page 4 of 7

\begin{tabular}{|c|c|c|c|c|c|}
\hline & & & Incidence (1:) & & \\
\hline & $\mathbf{N}$ & $\%$ & This Report & Previously Reported & References \\
\hline All CV Defects & 40 & 35.1 & 3 & $123-168$ & Bound and Logan, 1977 \\
\hline All Major Vessel & 15 & 13.2 & 8 & & \\
\hline Aberrant Right Subclavian Artery & 5 & 4.4 & 23 & $50-250$ & \\
\hline All Vena Cava & 6 & 5.3 & 19 & & \\
\hline Left SVC only & 0 & 0.0 & NA & 333 & Mowery and others, 2006 \\
\hline Bilateral SVC & 6 & 5.3 & 19 & 333 & Albay and others, 2006 \\
\hline Left IVC & 1 & 0.9 & 114 & 145 & \\
\hline Double IVC & 0 & 0.0 & NA & 97 & \\
\hline Interrupted IVC+Azygous Continuation & 1 & 0.9 & 114 & 1250 & Ueda and others, 1983 \\
\hline AP Collateral & 2 & 1.8 & 57 & NA & \\
\hline PAPVR & 1 & 0.9 & 114 & 12500 & http://emedicine.medscape.com \\
\hline Hypoplastic Aortic Arch & 1 & 0.9 & 114 & NA & \\
\hline All Valves & 3 & 2.6 & 38 & & \\
\hline Pulm Valve Stenosis & 3 & 2.6 & 38 & $1000-2000$ & http://www.pediatricheartspecialists.com \\
\hline All Septal Defects & 31 & 27.2 & 4 & & \\
\hline ASD & 15 & 13.2 & 8 & $167-2122$ & Bound and Logan, 1977 \\
\hline VSD & 14 & 12.3 & 8 & $19-422$ & Meberg, 2008 \\
\hline AVC & 2 & 1.8 & 57 & 2222 & Bound and Logan, 1977 \\
\hline All Other CHDs & 3 & 2.6 & & & \\
\hline Dextrocardia & 1 & 0.9 & 114 & 12019 & Bohun, 2007 \\
\hline Tet of Fallot & 1 & 0.9 & 114 & $238-2518$ & Bound and Logan, 1977 \\
\hline DORV & 1 & 0.9 & 114 & 11222 & Mitchell and others, 1971 \\
\hline All patients with foregut malformations & 114 & & & & \\
\hline
\end{tabular}

Table 2: Incidence of cardiac or major vascular anomalies in the foregut malformation population.

atresia-tracheoesophageal fistula, duodenal atresia, and congenital diaphragmatic hernia all had considerably higher length of stay as well as higher proportions requiring feeding and respiratory support at discharge.

We further compared the outcomes for the diagnoses in table $3 \mathrm{a}$ separated in two subgroups: foregut malformations in combination ("multiple") and those that occur as the patient's sole foregut malformation ("isolated"; Table 3b). Length of stay and need for respiratory and/or feeding support were highest for $\mathrm{CDH}$ and lowest for malrotation (Table 3b). Patients with any isolated foregut defect had shorter length of stay as well as lower need for feeding and/or respiratory support at discharge compared to patients with multiple congenital foregut defects (Table 3b). Length of stay was significantly increased for multiple categories of malrotation and laryngomalacia when compared to patients with these diagnoses in isolation. Trends toward increased feeding and respiratory support were seen in the multiple diagnosis category for malrotation, laryngomalacia, EA-TEF, $\mathrm{CDH}$, and duodenal atresia. Thus foregut defects in isolation convey less morbidity than when present in combination for patients.

\section{Discussion}

We took advantage of our population-based, geographically defined service area to generate the incidence and associated morbidity and mortality of congenital foregut malformations. We are the first to report the aggregate foregut malformation incidence of 1 in 801, which places aggregate foregut field defects among the more common congenital birth defects such as cleft lip/palate (1 in 940) and Down syndrome ( 1 in 737 ) [37]. We found airway malacias to be the most common congenital foregut malformations and provide previously unreported incidences of other less common malformations (esophageal web, bronchus suis, sequestration, microgastria, and annular pancreas).

We note that the majority of foregut malformation incidences fell below published frequencies (Table 1). This is likely due to our inclusion of foregut diagnoses (e.g., congenital hypothyroidism) that do not always obligate admission tertiary care center NICU. It is also possible that our region may have generally lower incidences for at least some of these conditions. In addition, we only included neonates who survived birth and transfer for admission to the CCHMC NICU; thus more severe, lethal malformations were likely missed. Two exceptions found to this study trend were: (1) duodenal atresia which had an incidence similar to those previously published by other epidemiologic studies [38,39] and (2) congenital diabetes mellitus, which occurs once in 400,000 patients (which exceeds the number of patients evaluated by this study) [40]. The incidences reported here may be most relevant in terms of estimating the size of the clinically significant patient populations needed for future molecular studies.

Some conditions (particularly the airway malaciaslaryngomalacia, tracheomalacia, and bronchomalacia) have been argued to reflect postnatal airway injury rather than primary fetal malformation [41]. This study revealed several instances, however, where the clinical symptoms and diagnosis preceded any possible airway trauma (e.g., intubation and mechanical ventilation, data not shown). Future work will focus on the aggregate incidence of these conditions as well as on establishing whether or not their diagnosis preceded any observable postnatal airway injury.

All the associated foregut malformations noted in our cohort have been previously noted in other research. Airway malacias (laryngomalacia, tracheomalacia, bronchomalacia) coincided: (1) with one another [42], (2) with esophageal atresia and tracheoesophageal fistula [43], and (3) with congenital diaphragmatic hernia [44]. We also observed esophageal atresia with tracheoesophageal fistula frequently as expected from previous reports [45], and annular pancreas in $18 \%$ of the eleven duodenal atresia patients $[39,46]$. We conclude that foregut malformations often coincide, although no new associations were identified here. These data support the idea of 
Citation: Kenny AP, Tabangin M, Hall E, Woodrooffe K, Lai W, et al. (2013) Cincinnati Regional Incidence, Morbidity, and Mortality of Neonatal Foregut Defects and High Coincidence with Cardiovascular Malformations. J Neonatal Biol 2: 115. doi:10.4172/2167-0897.1000115

Page 5 of 7

a) Aggregate Congenital Foregut Malformation Neonatal Morbidity and Mortality with Diagnosis Subgroupa Comparison to Pyloric Stenosis.

\begin{tabular}{|c|c|c|c|c|c|c|c|}
\hline & \multirow{2}{*}{$\begin{array}{l}\text { All congenital } \\
\text { foregut } \\
\text { malformations } \\
\mathrm{N}=114\end{array}$} & \multicolumn{5}{|c|}{ Most common congenital foregut diagnoses ${ }^{a}$} & \multirow{2}{*}{$\begin{array}{l}\text { Pyloric stenosis } \\
\qquad \mathrm{N}=16\end{array}$} \\
\hline & & $\begin{array}{l}\text { Malrotatio } \\
\quad \mathrm{N}=20\end{array}$ & $\begin{array}{c}\text { Laryngomalacia } \\
\mathrm{N}=18\end{array}$ & $\begin{array}{c}\text { EA-TEF }^{\mathrm{b}} \\
\mathrm{N}=12\end{array}$ & $\begin{array}{c}\text { Duodenal } \\
\text { Atresia } \mathrm{N}=5\end{array}$ & $\mathrm{CDH}^{\mathrm{b}} \mathrm{N}=4$ & \\
\hline Admission Day of Life, median [IQR] & $1[0,9]$ & $1.5[1,5]$ & $3.5[1,23]$ & $0[0,2]^{\mathrm{d}}$ & $0[0,1]$ & $0[0,0.5]$ & $26[13,55]$ \\
\hline Length of stay, median [IQR] & $32[18,87]$ & $17[7,27]$ & $21.5[9,44]$ & $24[20,31.5]$ & $43[36,64]$ & $20.5[12.5,27]$ & $6.5[3,26.5]$ \\
\hline Mortality, n (\%) & $8(7)$ & $1(5)^{c}$ & 0 & $1(8.3)^{c}$ & $1(20)^{c}$ & $2(50)^{c}$ & 0 \\
\hline \multicolumn{8}{|l|}{ Discharged with: } \\
\hline Feeding support, $\mathrm{n}(\%)$ & $53(51)$ & $0^{c}$ & $11(61.1)^{d}$ & $3(27.3)^{\mathrm{c}}$ & $1(25)^{c}$ & $1(50)^{c}$ & $2(12.5)$ \\
\hline Respiratory support, n (\%) & $28(27)^{c}$ & $0^{c}$ & $3(16.7)^{c}$ & $1(9.1)^{c}$ & $0^{c}$ & $1(50)^{c}$ & $1(6.3)$ \\
\hline
\end{tabular}

aDiagnosis subgroups do not include infants with multiple foregut diagnoses

${ }^{\mathrm{b}}$ Abbreviations: $\mathrm{EA}-\mathrm{TEF}=$ Esophageal Atresia and Tracheoesophageal Fistula, $\mathrm{CDH}=\mathrm{Congenital}$ Diaphragmatic Hernia

'Fisher's Exact test

${ }^{d}$ Significantly differs from Pyloric stenosis after adjusting for multiple comparisons, $p \leq 002$

b) Congenital Foregut Malformation Neonatal Morbidity and Mortality: Isolated vs Multiple Malformations.

\begin{tabular}{|c|c|c|c|c|c|c|c|c|}
\hline & \multicolumn{2}{|c|}{ All congenital foregut malformations } & \multicolumn{2}{|c|}{ Malrotation } & \multicolumn{2}{|c|}{ Laryngomalacia } & \multicolumn{2}{|c|}{ EA-TEFa } \\
\hline & Isolated & Multiple & Isolated & Multiple & Isolated & Multiple & Isolated & Multiple \\
\hline $\mathrm{N}$ & 76 & 38 & 20 & 5 & 18 & 11 & 12 & 9 \\
\hline Admission Day of Life, median [IQR] & $2[0,10]$ & $1[0,8]$ & $1.5[1,5]$ & $0[0,1]$ & $3.5[1,23]$ & $8[0,35]$ & $0[0,2]$ & $0[0,0.5]$ \\
\hline Length of stay, median [IQR] & $24[11.5,43.5]$ & $99[49,164]^{\mathrm{c}}$ & $17[7,27]$ & $62[46,78]^{\mathrm{c}}$ & $21.5[9,44]$ & $98[50,193]^{\mathrm{c}}$ & $24[20,31.5]$ & $67[46,111]$ \\
\hline Mortality, n (\%) & $5(6.6)$ & $3(7.9)^{b}$ & $1(5)$ & $1(20)^{b}$ & 0 & 0 & $1(8.3)$ & $1(11.1)^{b}$ \\
\hline Discharged with: & 70 & 34 & & & & & & \\
\hline Feeding support, n (\%) & $24(34.3)$ & $29(85.3)^{c}$ & 0 & $3(75)^{b}$ & $11(61.1)$ & $11(100)^{b}$ & $3(27.3)$ & $4(57.1)^{b}$ \\
\hline Respiratory support, n (\%) & $11(15.7)$ & $17(50)^{c}$ & 0 & $1(25)^{\mathrm{b}}$ & $3(16.7)$ & $8(72.7)^{b}$ & $1(9.1)$ & $1(14.3)^{b}$ \\
\hline
\end{tabular}

aAbbreviations: EA-TEF=Esophageal Atresia and Tracheoesophageal Fistula, $\mathrm{CDH}=$ Congenital Diaphragmatic Hernia

${ }^{\text {b}}$ Fisher's Exact test

'Significantly differs from isolated diagnosis after adjusting for multiple comparisons, $p \leq 002$

\begin{tabular}{|c|c|c|c|c|}
\hline & \multicolumn{2}{|c|}{ Duodenal Atresia } & \multicolumn{2}{|c|}{$\mathrm{CDHa}$} \\
\hline & Isolated & Multiple & Isolated & Multiple \\
\hline $\mathrm{N}$ & 5 & 6 & 4 & 7 \\
\hline Admission Day of Life, median [IQR] & $0[0,1]$ & $0[1,2]$ & $0[0,0.5]$ & $0[0,0]$ \\
\hline Length of stay, median [IQR] & $43[36,64]$ & $67[34,256]$ & $20.5[12.5,27]$ & $187[119,255]$ \\
\hline Mortality, n (\%) & $1(20)$ & $1(16.7)^{b}$ & $2(50)$ & $0^{\mathrm{b}}$ \\
\hline \multicolumn{5}{|l|}{ Discharged with: } \\
\hline Feeding support, n (\%) & $1(25)$ & $4(80)^{b}$ & $1(50)$ & $7(100)^{b}$ \\
\hline Respiratory support, n (\%) & 0 & $3(60)^{b}$ & $1(50)$ & $4(57.1)^{b}$ \\
\hline
\end{tabular}

aAbbreviations: EA-TEF=Esophageal Atresia and Tracheoesophageal Fistula, $\mathrm{CDH}=$ Congenital Diaphragmatic Hernia

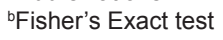

'Significantly differs from isolated diagnosis after adjusting for multiple comparisons, $p \leq 002$

Table 3: Patient characteristics, morbidity and mortality.

"field defect"[47,48]; that foregut malformations arise early in the first trimester from defective development of a common progenitor tissue that gives rise to more than one foregut organ $[12,49]$. In our study, only two foregut malformations occurred exclusively as isolated defects in our population: Congenital Pulmonary Adenomatoid Malformation (CPAM) and bronchopulmonary sequestration. They have been associated with other congenital foregut malformations in previous epidemiologic studies [50,51], and are not reported here here likely due to their low coincidence in our relatively small study population. However, molecular and developmental links between these associations will be a ripe area for future investigation [52].

We observed an increased coincidence of cardiovascular malformations with congenital foregut malformations, particularly vena caval anomalies (bilateral SVC or Left SVC) and septal defects (ASD and VSD). 43\% of 21 patients with esophageal atresiatracheoesophageal fistula had cardiovascular malformations (ASD, VSD, aberrant subclavian, aberrant vena cava), consistent with previous reports [53]. Fifty-five percent of the 11 patients with duodenal atresia had coincident cardiovascular malformations (including ASD, VSD, aberrant subclavian, aberrant vena cava, anomalous pulmonary venous return); these patients all had trisomy 21 (data not shown), which has well established associated cardiovascular anomalies [54].

Nearly one third $(29 \% ; 14 / 48)$ of NICU patients with a diagnosis of airway malacias had a concurrent cardiovascular defect (ASD in 6 , VSD in 7 , aberrant subclavian artery in 3, aberrant superior vena cava in 4, tetralogy of Fallot in 1), and these associations have not previously been reported. This was surprising given the perception that these anomalies might arise not as congenital malformations but as a consequence of incidental airway injury or trauma which would come from the respiratory management required for these patients [41]. The observed coincidence instead provides clinical evidence supporting a possible developmental association between these different organ malformations.

Other foregut malformation diagnoses observed to be 
Citation: Kenny AP, Tabangin M, Hall E, Woodrooffe K, Lai W, et al. (2013) Cincinnati Regional Incidence, Morbidity, and Mortality of Neonatal Foregut Defects and High Coincidence with Cardiovascular Malformations. J Neonatal Biol 2: 115. doi:10.4172/2167-0897.1000115

Page 6 of 7

associated with cardiovascular malformations included congenital diaphragmatic hernia [55], bronchus suis, annular pancreas [56], and congenital hypothyroidism $[57,58]$. We conclude that cardiovascular malformations have a high coincidence with congenital foregut organ malformations, consistent with the concept that these malformations may well be linked through a shared developmental mechanism $[4$, 59].

Neonatologists are often the first physicians to care for many patients with congenital foregut malformations. Their prompt recognition and treatment as well as the provision of objective outcome data for anticipatory guidance will be of great value to the patients and their families. This study is the first of its type to quantify the morbidity and mortality of congenital foregut malformations in the neonate. In the outcome analysis undertaken here, we quantified the increased neonatal morbidity with these conditions. This work underscores the severe phenotype and clinical course of these conditions and highlights the increased burden to the health care system in general from neonatal foregut malformations. In conclusion, we have provided both anticipatory guidance related to these malformations as well as impetus for further research into their cause, management, and prevention.

\section{Acknowledgments}

We thank Jeffrey A Whitsett and Alan $\mathrm{H}$ Jobe for helpful discussions. We thank David Jones for help with CCPOP Region maps, which served as a template for Figure 1. APK is supported by a CCHMC Procter Scholarship and NIH K08 HL105661 Career Development Award.

\section{References}

1. Kluth D, Lambrecht W (1997) Applied embryology in pediatric surgery. Eur J Pediatr Surg 7: 196-203.

2. Centers for Disease Control and Prevention (CDC) (2008) Update on overall prevalence of major birth defects--Atlanta, Georgia, 1978-2005. MMWR Morb Mortal Wkly Rep 57: 1-5.

3. Disabilities DoBDaD (2011) Facts about Birth Defects. Atlanta

4. Zorn AM, Wells JM (2009) Vertebrate endoderm development and organ formation. Annu Rev Cell Dev Biol 25: 221-251.

5. Tremblay KD (2010) Formation of the murine endoderm: lessons from the mouse, frog, fish, and chick. Prog Mol Biol Transl Sci 96: 1-34.

6. Kovesi T, Rubin S (2004) Long-term complications of congenital esophageal atresia and/or tracheoesophageal fistula. Chest 126: 915-925.

7. Tremblay KD (2011) Inducing the liver: understanding the signals that promote murine liver budding. J Cell Physiol 226: 1727-1731.

8. Metzger R, Wachowiak R, Kluth D (2011) Embryology of the early foregut. Semin Pediatr Surg 20: 136-144.

9. Wells JM, Melton DA (2000) Early mouse endoderm is patterned by soluble factors from adjacent germ layers. Development 127: 1563-1572.

10. Wandzioch E, Zaret KS (2009) Dynamic signaling network for the specification of embryonic pancreas and liver progenitors. Science 324: 1707-1710.

11. Shannon JM, Hyatt BA (2004) Epithelial-mesenchymal interactions in the developing lung. Annu Rev Physiol 66: 625-645.

12. Kenny AP, Crimmins NA, Mackay DJ, Hopkin RJ, Bove KE, et al. (2009) Concurrent course of transient neonatal diabetes with cholestasis and paucity of interlobular bile ducts: a case report. Pediatr Dev Pathol 12: 417-420.

13. Kenny AP, Rankin SA, Allbee AW, Prewitt AR, Zhang Z, et al. (2012) Sizzledtolloid interactions maintain foregut progenitors by regulating fibronectindependent BMP signaling. Dev Cell 23: 292-304.

14. Ackerman KG, Pober BR (2007) Congenital diaphragmatic hernia and pulmonary hypoplasia: new insights from developmental biology and genetics. Am J Med Genet C Semin Med Genet 145C: 105-108.

15. Ackerman KG, Herron BJ, Vargas SO, Huang H, Tevosian SG, et al. (2005)
Fog2 is required for normal diaphragm and lung development in mice and humans. PLoS Genet 1: 58-65.

16. Felix JF, Keijzer R, van Dooren MF, Rottier RJ, Tibboel D (2004) Genetics and developmental biology of oesophageal atresia and tracheo-oesophageal fistula: lessons from mice relevant for paediatric surgeons. Pediatr Surg Int 20: 731-736.

17. Crisera CA, Longaker MT, Gittes GK (1999) Molecular approaches to understanding organogenesis. Semin Pediatr Surg 8: 109-118.

18. Freedom RM, Yoo SJ, Goo HW, Mikailian H, Anderson RH (2006) The bronchopulmonary foregut malformation complex. Cardiol Young 16: 229251.

19. Brunner HG, van Bokhoven H (2005) Genetic players in esophageal atresia and tracheoesophageal fistula. Curr Opin Genet Dev 15: 341-347.

20. Kantarci S, Ackerman KG, Russell MK, Longoni M, Sougnez C, et al. (2010) Characterization of the chromosome $1 \mathrm{q} 41 \mathrm{q} 42.12$ region, and the candidate gene DISP1, in patients with CDH. Am J Med Genet A 152A: 2493-2504

21. Pober BR (2008) Genetic aspects of human congenital diaphragmatic hernia. Clin Genet 74: 1-15.

22. Geneviève D, de Pontual L, Amiel J, Lyonnet S (2011) Genetic factors in isolated and syndromic esophageal atresia. J Pediatr Gastroenterol Nutr 52 Suppl 1: S6-8.

23. Felix JF, de Jong EM, Torfs CP, de Klein A, Rottier RJ, et al. (2009) Genetic and environmental factors in the etiology of esophageal atresia and/or tracheoesophageal fistula: an overview of the current concepts. Birth Defects Res A Clin Mol Teratol 85: 747-754.

24. Zeidan S, Hery G, Lacroix F, Gorincour G, Potier A, et al. (2009) Intralobar sequestration associated with cystic adenomatoid malformation: diagnostic and thoracoscopic pitfalls. Surg Endosc 23: 1750-1753.

25. Shaw-Smith C (2010) Genetic factors in esophageal atresia, tracheoesophageal fistula and the VACTERL association: roles for FOXF1 and the $16 q 24.1$ FOX transcription factor gene cluster, and review of the literature. Eur J Med Genet 53: 6-13.

26. Schultheiss TM, Xydas S, Lassar AB (1995) Induction of avian cardiac myogenesis by anterior endoderm. Development 121: 4203-4214.

27. Lammert E, Cleaver O, Melton D (2001) Induction of pancreatic differentiation by signals from blood vessels. Science 294: 564-567.

28. Albay S, Cankal F, Kocabiyik N, Yalcin B, Ozan H (2006) Double superior vena cava. Morphologie 90: 39-42.

29. Mowery N, Billmire DF, Schamberger M, Szotek P, West KW, et al. (2006) Incidence of persistent left superior vena cava in esophageal atresia. Pediatr Surg 41: 484-486.

30. Bound JP, Logan WF (1977) Incidence of congenital heart disease in Blackpool 1957-1971. Br Heart J 39: 445-450.

31. Mitchell SC, Korones SB, Berendes HW (1971) Congenital heart disease in 56,109 births. Incidence and natural history. Circulation 43: 323-332.

32. Meberg A, Otterstad JE, Frøland G, Sørland S, Nitter-Hauge S (1994) Increasing incidence of ventricular septal defects caused by improved detection rate. Acta Paediatr 83: 653-657.

33. Roguin N, Du ZD, Barak M, Nasser N, Hershkowitz S, et al. (1995) High prevalence of muscular ventricular septal defect in neonates. J Am Coll Cardiol 26: 1545-1548.

34. Hoffman JI, Kaplan S (2002) The incidence of congenital heart disease. J Am Coll Cardiol 39: 1890-1900.

35. Bohun CM, Potts JE, Casey BM, Sandor GG (2007) A population-based study of cardiac malformations and outcomes associated with dextrocardia. Am J Cardiol 100: 305-309.

36. Bound JP, Logan WF (1977) Incidence of congenital heart disease in Blackpool 1957-1971. Br Heart J 39: 445-450.

37. Parker SE, Mai CT, Canfield MA, Rickard R, Wang Y, et al. (2010) Updated National Birth Prevalence estimates for selected birth defects in the United States, 2004-2006. Birth Defects Res A Clin Mol Teratol 88: 1008-1016. 
Citation: Kenny AP, Tabangin M, Hall E, Woodrooffe K, Lai W, et al. (2013) Cincinnati Regional Incidence, Morbidity, and Mortality of Neonatal Foregut Defects and High Coincidence with Cardiovascular Malformations. J Neonatal Biol 2: 115. doi:10.4172/2167-0897.1000115

Page 7 of 7

38. Forrester MB, Merz RD (2004) Population-based study of small intestinal atresia and stenosis, Hawaii, 1986-2000. Public Health 118: 434-438.

39. Fonkalsrud EW, DeLorimier AA, Hays DM (1969) Congenital atresia and stenosis of the duodenum. A review compiled from the members of the Surgical Section of the American Academy of Pediatrics. Pediatrics 43: 7983.

40. von Mühlendahl KE, Herkenhoff H (1995) Long-term course of neonatal diabetes. N Engl J Med 333: 704-708.

41. Garcia H, Ramirez-San Juan H, Ramirez Figueroa J, Villegas-Silva R, Madrigal Muniz O (2012) Frequency and type of airway injury identified by bronchoscopic examination in newborns with prolonged endotracheal intubation in a neonatal intensive care unit. Bol Med Hosp Infant Mex. 69: 376-381.

42. Vijayasekaran D, Gowrishankar NC, Kalpana S, Vivekanandan VE, Balakrishnan MS, et al. (2010) Lower airway anomalies in infants with laryngomalacia. Indian J Pediatr 77: 403-406.

43. Boogaard R, Huijsmans SH, Pijnenburg MW, Tiddens HA, de Jongste JC, et al. (2005) Tracheomalacia and bronchomalacia in children: incidence and patient characteristics. Chest 128: 3391-3397.

44. Cunningham $S$ (2005) Two imaging techniques to find too flexible an airway: looking for malacia. Arch Dis Child Fetal Neonatal Ed 90: F284-285.

45. Ioannides AS, Copp AJ (2009) Embryology of oesophageal atresia. Semin Pediatr Surg 18: 2-11.

46. Clark JF, Hales E, Ma P, Rosser SB (1984) Duodenal atresia in utero in association with Down's syndrome and annular pancreas. J Natl Med Assoc 76: 190-192.

47. Opitz JM (1985) The developmental field concept. Am J Med Genet 21: 1-11.

48. Martinez-Frias ML (1994) Developmental field defects and associations: epidemiological evidence of their relationship. American journal of medical genetics 49: 45-51.
49. Deutsch G, Jung J, Zheng M, Lóra J, Zaret KS (2001) A bipotential precursor population for pancreas and liver within the embryonic endoderm. Development 128: 871-881.

50. Newman B (2006) Congenital bronchopulmonary foregut malformations: concepts and controversies. Pediatr Radiol 36: 773-791.

51. Corbett HJ, Humphrey GM (2004) Pulmonary sequestration. Paediatr Respir Rev 5: 59-68.

52. de Jong EM, Felix JF, de Klein A, Tibboel D (2010) Etiology of esophageal atresia and tracheoesophageal fistula: "mind the gap". Curr Gastroenterol Rep 12: 215-222.

53. Chittmittrapap S, Spitz L, Kiely EM, Brereton RJ (1989) Oesophageal atresia and associated anomalies. Arch Dis Child 64: 364-368.

54. Freeman SB, Taft LF, Dooley KJ, Allran K, Sherman SL, et al. (1998) Population-based study of congenital heart defects in Down syndrome. Am J Med Genet 80: 213-217.

55. Fauza DO, Wilson JM (1994) Congenital diaphragmatic hernia and associated anomalies: their incidence, identification, and impact on prognosis. J Pediatr Surg 29: 1113-1117.

56. Merrill JR, Raffensperger JG (1976) Pediatric annular pancreas: twenty years' experience. J Pediatr Surg 11: 921-925.

57. Bamforth JS, Hughes I, Lazarus J, John R (1986) Congenital anomalies associated with hypothyroidism. Arch Dis Child 61: 608-609.

58. Olivieri A, Stazi MA, Mastroiacovo P, Fazzini C, Medda E, et al. (2002) A population-based study on the frequency of additional congenital malformations in infants with congenital hypothyroidism: data from the Italian Registry for Congenital Hypothyroidism (1991-1998). J Clin Endocrinol Metab 87: 557-562.

59. Postema PG, Rammeloo LA, Hruda J (2008) Clinical significance of a persistent left superior vena cava. Ultrasound Obstet Gynecol 31: 113-114. 